\title{
SOROPREVALÊNCIA DE Leptospira interrogans E FLAVIVIROSES EM EQUINOS DA CIDADE DE PELOTAS E REGIÃO, NO RIO GRANDE DO SUL
}

\author{
HACK, Jemhally Dillenburg ${ }^{1}$; \\ MOUSQUER, Mariana Andrade ${ }^{2}$; \\ RIES, Ananda Segabinazzi ${ }^{3}$; \\ DEWES, Caroline ${ }^{4}$; \\ SOUZA, Rafaela Pinto de ${ }^{1}$; \\ FERREIRA, Nathália Oliveira ${ }^{5}$; \\ BRUHN, Fábio Raphael Pascoti ${ }^{6}$; \\ NOGUEIRA, Carlos Eduardo Wayne ${ }^{7}$.
}

Recebido: $16 / 06 / 2018$

Aceito: $23 / 12 / 2018$

\begin{abstract}
${ }^{1}$ Médica Veterinária, Residente em Clínica Médica de Equinos, Universidade Federal de Pelotas (UFPEL); ${ }^{2}$ Médica Veterinária, Mestranda, Programa de Pós-Graduação em Veterinária/UFPEL; ${ }^{3}$ Médica Veterinária, Mestranda, Programa de Pós-Graduação em Veterinária, Universidade Federal de Santa Maria; ${ }^{4}$ Médica Veterinária, Doutoranda, Programa de Pós-Graduação em Veterinária/UFPEL; ${ }^{5}$ Graduanda, Faculdade de Veterinária/UFPEL; ${ }^{6}$ Professor adjunto, Faculdade de Veterinária/UFPEL ; Professor associado, Faculdade de Veterinária/UFPEL.
\end{abstract}

\section{RESUMO}

A leptospirose e as flaviviroses que acometem equinos são zoonoses de ocorrência mundial e de grande importância em saúde pública. Sendo assim, o objetivo deste estudo foi disponibilizar levantamento epidemiológico através de exame sorológico para triagem de Leptospira spp. e flaviviroses na região de Pelotas/RS e arredores, como os municípios mais próximos. Para isso, foram coletadas amostras sanguínea de 275 equinos, sendo 119 animais de propriedade de carroceiros da cidade de Pelotas e 156 animais apreendidos soltos nas rodovias e soltos dentro da cidade de Pelotas e Capão do Leão. Para o diagnóstico sorológico de leptospirose, foi utilizado o Teste de Aglutinação Microscópica (MAT), no qual $100 \%$ das amostras testadas apresentaram titulação mínima de 1:100 a diversos sorovares, e 4,72\% (13 animais) apresentaram sorologia superior a 1:800 em sorovares de importância clínica como L. interrogans Icterohaemorrhagiae, L. interrogans Canicola e L. interrogans Grippothyphosa. Frente ao teste de imunofluorescência indireta (IFI) foram identificados $1,8 \%$ de soropositivos (5 animais) para vírus do gênero Flavivirus. Pode-se observar no estudo a prevalência da Leptospira spp. em todos os animais avaliados e inferindo presença das flaviviroses na região. Com isso afirma-se a importância dos levantamentos epidemiológicos para prevenção e controle das zoonoses de importância em saúde pública.

Palavras-chave: Leptospirose. Flaviviridae. Equinos. Epidemiologia. Soroprevalência. 


\section{INTRODUÇÃO}

A leptospirose e as flaviviroses que acometem equinos são zoonoses de ocorrência mundial e de grande importância para a saúde pública. É papel do médico veterinário, juntamente com os demais profissionais da saúde, esclarecer detalhes sobre suas epidemiologias, formas de prevenção e de diagnóstico precoce (FARACO; SEMINOTTI, 2004; SCHMIDT, 2009). A leptospirose é causada por uma espiroqueta do gênero Leptospira (ELLIS, 1994; PIMENTEL et al., 2009), é endêmica no Brasil e apresenta maior prevalência nas zonas tropicais e subtropicais. Atualmente a L. interrogans foi reclassificada em 20 espécies as quais são distribuídas em mais de 260 sorovariedades, agrupadas em 23 sorogrupos (ADLER, 2010).

Os roedores desempenham um papel importante no ciclo da doença, albergando a bactéria nos túbulos renais antes de eliminá-la na urina, contaminando o ambiente (MIRAGLIA et al., 2013). Em equinos infectados pode ocorrer uveíte, aborto ou distúrbios reprodutivos, insuficiência renal e meningite, sendo que a maioria das infecções apresenta uma ausência de sinais clínicos (BAVERUD et al., 2009; JONES et al., 2000). Os fatores ecológicos e climáticos da região podem favorecer a sobrevivência do patógeno da leptospirose e dos vetores das flaviviroses. Particularmente nas capitais metropolitanas de baixa renda, nas quais as enchentes, associadas às condições de higiene e saneamento básico precário e a alta infestação de roedores infectados, levam ao aumento do número de casos de leptospirose em seres humanos (BRASIL, 2017).

O município de Pelotas é caracterizado por apresentar muitos animais utilizados na tração de carroças e charretes, estima-se em torno de três mil cavalos (VELHO et al., 2007). Esses animais mantêm contato com a população transitando por todo o município e redondezas, e, na maioria das vezes, não recebem quaisquer cuidados sanitários. Do mesmo modo, não realizam os exames exigidos pelo Ministério da Agricultura, Pecuária e Abastecimento para trânsito. Cavalos quando infectados com leptospiras, eliminam a bactéria não apenas em suas residências, mas em vários pontos do município por onde perambulam (HAMOND et al., 2012). Além disso, a alta pluviosidade da região facilita a disseminação das leptospiras que sobrevivem em meio úmido, e contribui para proliferação de mosquitos, como os vetores das flaviviroses (GOMES, 2002). 
De acordo com o Comitê Internacional em Taxonomia Viral (ICTV, 2018) no gênero Flavivirus estão classificadas aproximadamente 50 espécies de vírus de difícil identificação morfológica e taxonômicamente divididos em dez grupos antigenicamente relacionados, estando entre eles o grupo dos vírus da encefalite japonesa (JEV), formado entre outros, pelo vírus da encefalite Saint Louis (SLEV) e vírus da febre do Nilo Ocidental (WNV). O WNV e o SLEV são vírus zoonóticos de importância em sanidade animal (FLORES, 2009) e de relevância em equinos, sendo transmitidos principalmente por mosquitos comuns, como o Culex spp. (BRASIL, 2017). O ciclo viral é mantido entre culicídeos e aves, mas, incidentalmente, estes mosquitos podem transmitir os vírus a mamíferos, principalmente seres humanos e cavalos (FIGUEIREDO, 2007). Conforme descrito por Komar e Clark (2006) as aves migratórias foram responsáveis pela disseminação do WNV para o México, o Caribe, a América Central e a América do Sul e segundo informações do relatório anual de rotas e áreas de concentração de aves migratórias, a região de Pelotas e proximidades fazem parte da "Rota Brasil Central" e "Rota Atlântica", o que facilita a entrada de doenças, principalmente as virais (ARAUJO, 2011; OLIVEIRA et al., 2016).

Os equinos são altamente suscetíveis à infecção por flavivírus, mas a maioria dos infectados não apresenta sinais clínicos (OSTLUND et al., 2001), sendo que podem evoluir desde uma síndrome inespecífica, com regressão espontânea em uma a duas semanas, ou até a forma de encefalite, podendo deixar sequelas e levar à morte (CASSEB et al., 2013). Quando existem sinais clínicos, estes se caracterizam, principalmente, por ataxia, fraqueza, fasciculação muscular, debilidade generalizada, incoordenação dos membros e déficit de nervos cranianos. Conforme o flavivírus envolvido, os sinais clínicos podem variar (TROCK et al., 2001).

Alguns inquéritos sorológicos realizados em amostras de soro de cavalos em diversos estados do Brasil demonstraram a intensa co-circulação de flavivírus em nosso país. A soroprevalência do SLEV em equinos foi relatada nos estados de Minas Gerais, Rio de Janeiro, Mato Grosso do Sul, Paraíba, São Paulo e Pará (PAUVOLID-CORRÊA et al., 2010; RODRIGUES et al., 2010b; ROSA et al., 2013; SILVA, 2010). Como mencionado anteriormente, cavalos infectados por SLEV raramente desenvolvem sinais clínicos, no entanto, um caso 
neurológico fatal foi descrito em Minas Gerais (ROSA et al., 2013). Em 2018 houve registro de febre do Nilo Ocidental em um equino pela Secretaria de Estado da Saúde do Espírito Santo (BRASIL, 2018; SESA, 2018). Em humanos, dois casos de febre do Nilo Ocidental foram confirmados, ambos no estado do Piauí, em 2014 e 2017 (SESAPI, 2019). A encefalite Saint Louis também tem registros, tendo dois casos confirmados no estado do Pará e mais de dez casos confirmados no estado de São Paulo, sendo alguns casos confundidos clinicamente com dengue, mas confirmados por diagnóstico definitivo para SLEV (PACCA, 2013).

Devido ao grande número de equídeos na região sul do estado do Rio Grande do Sul, sendo uma área que sofre frequentes alagamentos e estando na rota de aves migratórias, revestese de grande importância o monitoramento epidemiológico de tais zoonoses, presentes em algumas regiões do Brasil. Este estudo teve como objetivo realizar a avaliação da presença de anticorpos para leptospirose e flaviviroses, obtendo um levantamento epidemiológico em equinos do município de Pelotas e regiões próximas.

\section{MATERIAL E MÉTODOS}

Este projeto foi aprovado pela Comissão de Ética em Experimentação Animal da Universidade Federal de Pelotas (CEEA/UFPEL), estando cadastrado sob o número 3256.

As 275 amostras deste trabalho foram coletadas conforme o cálculo amostral realizado com base em um valor esperado para a prevalência de $50 \%$, confiança de $95 \%$ e erro amostral de 6\%. A fórmula utilizada foi: $M=Z^{2}[P(1-P)] / E^{2}$, onde $M=0$ tamanho final da amostra, $Z=0$ nível de confiança, $P=$ a prevalência e $E=0$ erro amostral (SERGEANT, 2018). Assim, $M=$ $(1,96)^{2}[0,50(1-0,50)] /(0,06)^{2}$, onde $M=267$ equinos.

Para a realização deste estudo obtiveram-se amostras sanguíneas de 275 equinos, sem raça definida, sendo 110 fêmeas e 165 machos. Tanto animais castrados e não castrados, como fêmeas prenhes e não prenhes, com idade superior a dois anos de idade. Do total dos animais, 119 equinos são de proprietários carroceiros cadastrados no ambulatório Ceval do Hospital de Clinicas Veterinárias (HCV) que disponibilizaram voluntariamente seus animais para realização da coleta sanguínea. Este ambulatório faz parte de um projeto de extensão do HCV/UFPEL, que disponibiliza atendimento para famílias carentes cadastradas no projeto. 
Os animais do Ceval, utilizados neste trabalho, nasceram na região e permaneceram sem ser transportados para locais diferentes, transitando apenas nos municípios de Pelotas e Capão do Leão. Outros 52 animais do estudo foram apreendidos nas rodovias federais da região de Pelotas, sob jurisdição da Polícia Rodoviária Federal e da empresa concessionária ECOSUL (BR 116 Camaquã - Jaquarão e BR 392 Rio Grande - Santana da Boa Vista), e albergados no Centro Experimental da Palma/HCV/UFPEL. Os demais animais (104 equinos) foram apreendidos quando estavam soltos dentro das cidades de Pelotas e Capão do Leão, recolhidos pelas respectivas prefeituras municipais. Os apreendidos em Pelotas foram albergados na Hospedaria de Grandes Animais do município, e os apreendidos no Capão do Leão foram albergados no Centro Experimental da Palma/HCV/UFPEL. Os animais desse grupo não apresentam histórico sobre a origem e os locais onde viveram.

Todos os animais foram resenhados para identificação e avaliados clinicamente através de exame clínico geral como descrito por Speirs (1999). Os que apresentaram padrões clínicos dentro da normalidade para a espécie e com autorização do responsável participaram do estudo.

A coleta foi realizada em um único momento, logo da apreensão do animal ou durante a consulta no ambulatório Ceval, com o animal em estação, contido mecanicamente através de um buçal, e, quando necessário, eram colocados em um tronco de contenção especifico para equinos. Após a contenção, era realizada punção venosa diretamente da veia jugular externa utilizando o sistema BD Vacutainer ${ }^{\circledR}$. Os tubos permaneceram em temperatura ambiente por uma hora para a separação do soro, após foram centrifugados a $800 \mathrm{~g}$ durante dez minutos. Os soros sanguíneos foram armazenados em microtubos Epperdorf ${ }^{\circledR}$ e mantidos a $-20^{\circ} \mathrm{C}$ até o momento das análises.

Após o término de todas as coletas, as amostras foram enviadas, conforme normas descritas para a conservação do material no transporte (ANVISA, 2014), para o Laboratório do Grupo de Estudos de Doenças Transmitidas por Animais (GEDTA/UFPEL), onde foi realizado o diagnóstico sorológico para leptospirose através do Teste de Aglutinação Microscópica (MAT), considerado teste padrão ouro pela Organização Mundial da Saúde Animal (OIE); e para o Setor de Virologia da Universidade Federal de Santa Maria (UFSM) para o diagnóstico 
sorológico das flaviviroses através do teste de Imunofluorescência Indireta (IFI).

No MAT, os soros sanguíneos foram submetidos à pesquisa de aglutininas anti-leptospiras em diluições crescentes, de 1:100 até 1:3200, considerando-se como resultado positivo as aglutinações iguais ou superiores a 1:100 (SANTA ROSA, 1970). Os soros foram inicialmente diluídos a 1:50 em PBS estéril, $\mathrm{pH} 7,2$, e o teste foi considerado reagente quando houve aglutinação de $50 \%$ ou mais das leptospiras em relação ao controle.

Os soros foram testados com um painel de antígenos formados por 10 sorovares de leptospiras vivas: Australis, Autumnalis, Bratislava, Bataviae, Copenhageni, Grippothyphosa, Hardjo, Pomona, Pyrogenes e Icterohaemorrhagiae, os quais foram cedidos pela Fundação Oswaldo Cruz (FIOCRUZ/RJ), acrescidos do sorovar saprófita Patoc, recomendado pela Organização Mundial de Saúde (WHO, 2003), e de dois isolados locais, Ballum 4E e Canicola Kito (SILVA et al., 2008). Conforme Faine et al. (1999), as leptospiras foram cultivadas em meio EMJH (Ellinghausen-McCullough Johnson Harris, Difco, Maryland, USA) líquido, a uma temperatura de $29{ }^{\circ} \mathrm{C}$ e repicadas a cada sete dias, até a concentração de $1-2 \times 10^{8}$ leptospiras $/ \mathrm{mL}$.

No teste de IFI foi utilizado como antígeno um vírus da febre amarela recombinante (rYFV), que expressa as proteínas do envelope (prM e E) do vírus do Nilo Ocidental (WNV) (ARENHART et al., 2012). O vírus foi amplificado em células BHK-21, que foram fixadas em lâminas multispot para uso como antígeno na imunofluorescência. As amostras de soro-teste (soro dos equinos) foram diluídas 1:20 em meio essencial mínimo e utilizadas como anticorpo primário, sendo incubados por $1 \mathrm{~h}$ a $37^{\circ} \mathrm{C}$. Em seguida as lâminas foram lavadas e incubadas com anticorpo secundário anti-IgG de equino conjugado com fluoresceína, diluído 1:200. Após $1 \mathrm{~h}$ de incubação a $37^{\circ} \mathrm{C}$, as lâminas foram lavadas (10x PBS, 10x água destilada) e coradas por 5 minutos em solução de Evans blue. Em seguida, as lâminas foram novamente lavadas e visualizadas em microscópio de imunofluorescência. Como controle positivo foi utilizado o soro de um equino imunizado com vacina comercial para o WNV. Como controle negativo, foi utilizado o soro de um equino hígido. Ambos foram diluídos 1:20, conforme diluição das amostras-teste.

As soroprevalências e seu intervalo de confiança a 95\% (IC. 95\%) foram calculadas conforme 
descrito por Reiczigel et al. (2010).

\section{RESULTADOS E DISCUSSÃO}

Para Leptospira interrogans todos os 275 animais (100\%; IC. 95\%=98,6 - 100,0\%) testados apresentaram titulação mínima de 1:100 e nenhum apresentou sinal clínico compatível com a doença. Os sorovares com maior incidência foram $L$. interrogans Canicola seguido de $L$. interrogans Hardjo, L. interrogans Ballun 4E (isolado local) e L. interrogans Autumnalis. Dentre os maiores títulos (1:1600) estão: L. interrogans Icterohaemorrhagiae, L. Interrogans Copenhageni e L. interrogans Bratislava, tendo esta titulação um animal para cada sorovar citado. Títulos de 1:800 foram evidenciados em um animal para o sorovar L. interrogans Canicola, um L. interrogans Autumnalis e L. interrogans Bratislava, um L. interrogans Grippothyposa, dois animais para L. interrogans Australis, L. interrogans Copenhageni e $L$. interrogans Ballum (Figuras 1 e 2).

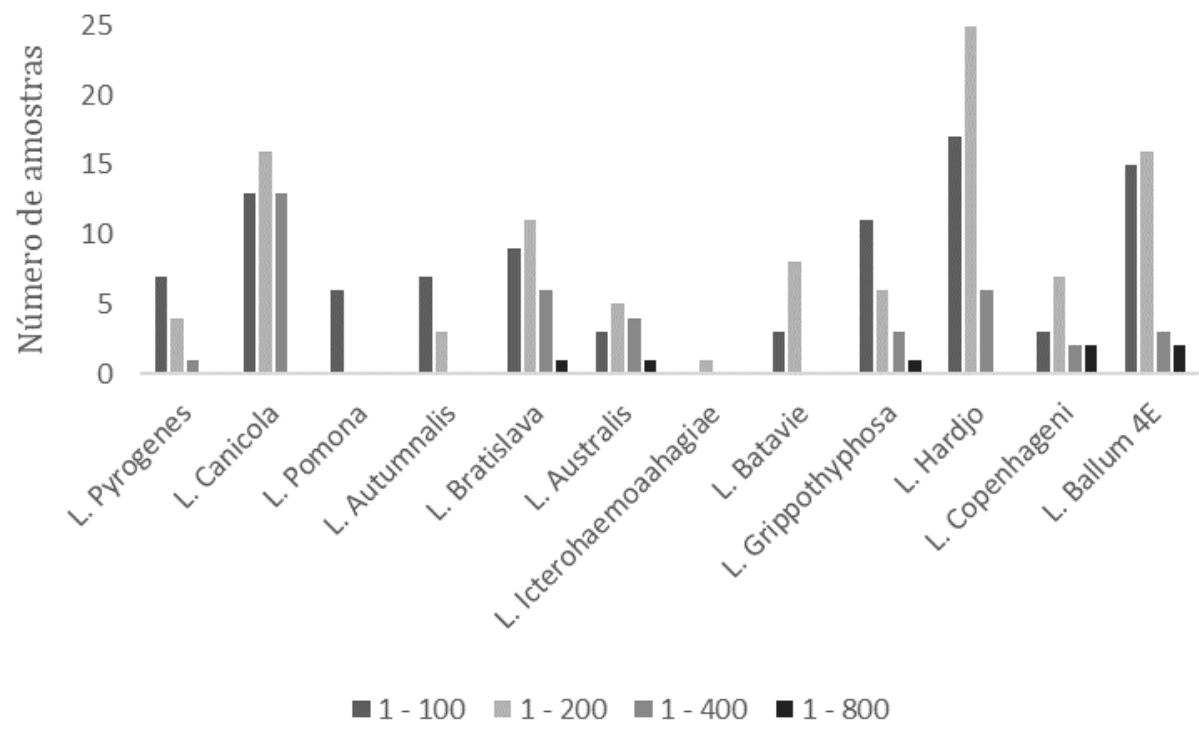

Figura 1 - Gráfico demonstrativo das amostras reativas para leptospirose em equinos apreendidos nas rodovias da região de Pelotas, na zona urbana de Pelotas e zona urbana do Capão do Leão 


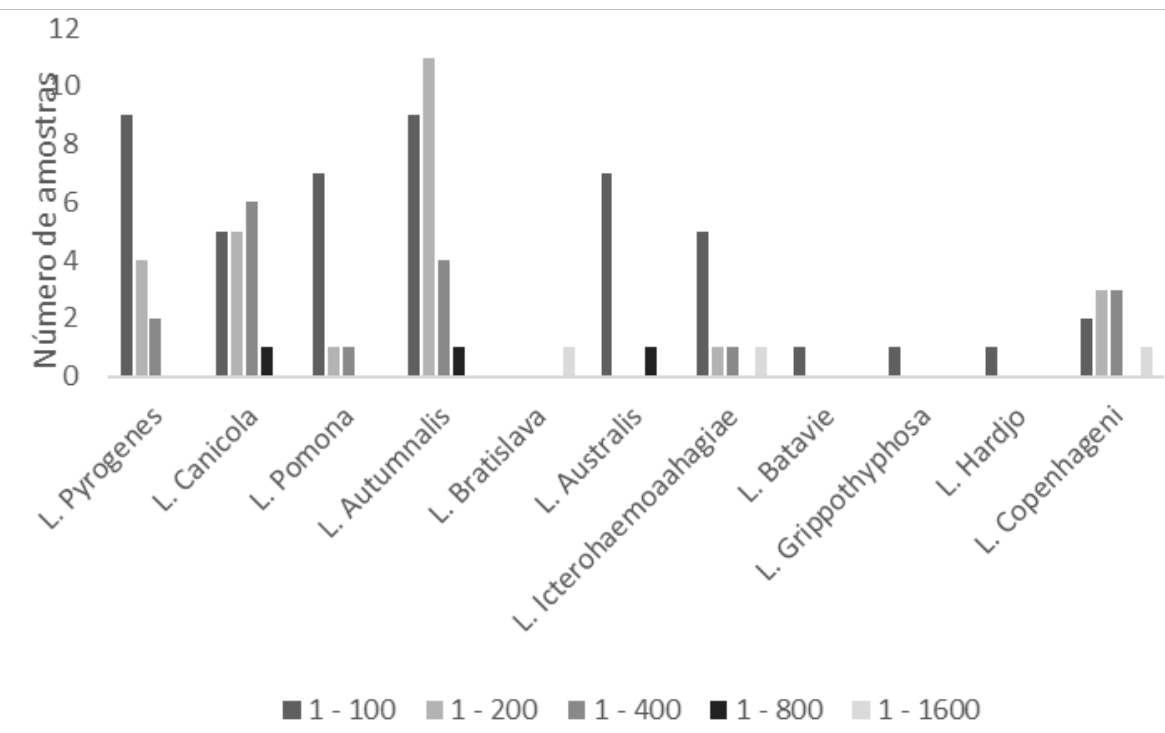

Figura 2 - Gráfico demonstrativo dos resultados da avaliação sorológica para leptospirose dos equinos de propriedade particular atendidos no Ambulatório Ceval/HCV/UFPEL.

Apesar de não existir obrigatoriamente uma relação entre título sorológico e infecção, Lilebaum et al. (1995) considera positivo quando o título for igual ou superior a 1:200, embora diluições com títulos positivos de 1:100 possam ser relevantes para a saúde do rebanho. Outros autores aceitam diferentes valores de título para considerar positivo como: 1:200, 1:400 e 1:800 (WHO, 2003). Os animais avaliados não apresentavam sintomatologia clínica no momento da coleta, o que não exclui a possibilidade da doença, a qual ocorre mais comumente de forma assintomática nos equinos. A ocorrência desta zoonose é significativamente maior em países de clima tropical do que nos de clima temperado devido principalmente às condições de temperatura e umidade, que favorecem a longa sobrevida das leptospiras no meio ambiente (HAGIWARA, 2003). A quantidade de lixo nas ruas propicia o aparecimento de roedores, sendo o rato de esgoto (Rattus norvegicus), o hospedeiro natural dos sorovares $L$. Icterohaemorrhagiae, L. Copenhageni e L. Pyrogenes, os quais comumente infectam os equinos e seres humanos. Este roedor não desenvolve a doença e libera a bactéria durante toda sua vida através da urina (MARTINS; CASTIÑEIRAS, 2009). Essa é a realidade das comunidades que vivem na periferia da cidade de Pelotas, sendo os cavalos utilizados como meio de transporte para coletar do lixo o material a ser reciclado.

O sorovar L. Interrogans Icterohaemorrhagiae apareceu em um equino com título de 1:1600. 
Dentre os sorovares da espécie interrogans, no Brasil, o sorovar Icterohaemorrhagiae parece ser o mais comum em humanos (BLAZIUS et al., 2005). Em 90\% dos pacientes com a doença, são observados sinais clínicos semelhantes ao da influenza, passando a doença muitas vezes despercebida (PAPPAS; CASCIO, 2006). O coeficiente médio de incidência anual em humanos é de 1,9/100.000 habitantes (BRASIL, 2014a), entretanto, não foi possível, neste trabalho, estabelecer essa relação.

Os grupos populacionais mais acometidos pela doença são aqueles que trabalham ou vivem em áreas sujeitas a enchentes, em precárias condições de moradia e/ou sem saneamento básico, em contato com água ou lama e/ou esgotos contaminados pela urina de roedores (FUNASA, 1997). Dos animais avaliados, grande parte deles eram de proprietários em total fragilidade social que sustentam suas famílias através da coleta seletiva de lixo para reciclagem. Estas pessoas e seus animais, cães, gatos, galinhas e cavalos, vivem nas margens do arroio São Gonçalo, que atravessa a cidade de Pelotas. Os cuidados sanitários são quase inexistentes, o clima é quente e temperado, a pluviosidade significativa ao longo do ano aumenta a incidência das enchentes, ou seja, diversos fatores criam condições propícias para a permanência e a infecção por leptospiras. A maior prevalência de animais reagentes a diversos sorovares nos equinos de propriedade de carroceiros é demonstrativo que a falta de cuidados sanitários, contato com lixo e enchentes propiciam o contágio e a infecção por esse agente.

Dentre os 275 equinos avaliados para presença de anticorpos contra vírus do gênero Flavivirus, $1,8 \%$ (IC. $95 \%=0,08-4,1 \%$ ) das amostras apresentaram resultados positivos (5 animais), também sem demonstrar sinais clínicos. Dois destes animais foram apreendidos pela empresa concessionária ECOSUL. Um deles é um equino macho, com cinco anos de idade que estava na BR 116, km 655, município de Jaguarão, no ano de 2015. O outro também é um equino macho, com três anos de idade, apreendido na BR 392, km 7, município de Pelotas, no ano de 2017. Estes animais encontram-se albergados no Centro Experimental da Palma/HCV/UFPEL desde a data de suas apreensões. Os demais equinos reagentes para flaviviroses são três machos, com idade entre 5 e 10 anos, de tutores carroceiros cadastrados no projeto Ambulatório Ceval/HCV/UFPEL. Dois cavalos pertencem a 
um tutor domiciliado no loteamento Barão de Mauá, no centro da cidade de Pelotas e o outro animal pertence ao tutor domiciliado na Rua do Pântano, bairro Porto, também da cidade de Pelotas. Esses três animais são utilizados em charrete para coleta de material reciclável, ficando albergados na área externa da residência de seus tutores, sendo que nunca circularam fora do município de Pelotas.

No teste de IFI usado para triagem das flaviviroses foi utilizado como antígeno um vírus recombinante da febre amarela que expressa as proteínas do envelope do WNV (ARENHART et al., 2012). Essas proteínas são as mais imunogênicas do vírus do Nilo Ocidental e, portanto, é contra elas que o organismo infectado produz a maior parte dos anticorpos. Porém, essas proteínas são muito similares estruturalmente com as proteínas de outros vírus do gênero Flavivirus, como os vírus do complexo da encefalite japonesa (JEV), entre outros, e, portanto, os anticorpos dos animais podem ter reagido de forma cruzada, não sendo possível especificar a qual vírus foi reativo. Segundo a Sociedade Brasileira de Patologia Clínica (SBPC, 2016) as metodologias indiretas podem apresentar resultados falsopositivos devido às denominadas reações cruzadas com outros vírus da mesma família, em particular os flavivírus. Para podermos afirmar qual vírus do gênero Flavivirus está envolvido em nosso estudo, o ideal seria a realização do teste de neutralização por redução de placas virais (PRNT), que é considerado o teste padrão ouro para esses vírus. No entanto, para a execução deste teste é fundamental possuir o vírus infeccioso/replicativo, o que é uma limitante para a maioria dos laboratórios brasileiros, principalmente em relação a vírus considerados exóticos no Brasil. Considerando esta limitação, e por ser um teste muito laborioso, não é utilizado como método diagnóstico principal nos laboratórios (MARTíNEZ et al., 2002).

A sensibilidade e a especificidade do teste de IFI utilizado neste estudo ainda não foram determinadas, havendo possibilidade da ocorrência de reações cruzadas com vírus que acometem equinos da família pesquisada (Flaviviridae). Porém, o trabalho demonstrou a presença dos flavivírus na região, assim como foi evidenciado por Vianna (2010), que de 1.775 equinos pesquisados nos estados do Paraná, Santa Catarina e Rio Grande do Sul, nos anos de 2007 e 2008, encontrou 254 (14,3\%) animais positivos para anticorpos anti- 
flavivírus.

Em 2011, foi relatada a primeira evidência sorológica do WNV em cavalos no Pantanal MatoGrossense (PAUVOLID-CORRÊA et al., 2011). Posteriormente, o vírus também foi detectado em frangos e cavalos no Mato Grosso do Sul e na Paraíba (MELANDRI et al., 2012; SILVA et al., 2013). Diversas pesquisas sorológicas em equinos de várias regiões brasileiras também demostraram a presença de anticorpos contra o SLEV, Pantanal (PAUVOLID-CORRÊA et al., 2010), Amazônia brasileira (RODRIGUES et al., 2010b), Mato Grosso (HEINEN et al., 2015) e Rio de Janeiro (CHALHOUB, 2017). Conforme Gould et al. (2003), os flavivírus estão presentes em todos os continentes com exceção da Antártida.

No ano de 2014, o primeiro caso confirmado de febre do Nilo Ocidental em humanos no Brasil foi evidenciado no estado do Piauí (BRASIL, 2014b). Em 2017, também no Piauí, outros dez casos suspeitos foram confirmados para flavivírus através de sorologia (SESAPI, 2017). Em 2017, no mesmo Estado, uma jovem que sofreu um quadro de paralisia muscular flácida aguda, teve a confirmação para WNV através da identificação de anticorpos neutralizantes contra o vírus (SESAPI, 2019).

Nos anos noventa, no estado do Pará, e em 2005, no estado de São Paulo, casos de encefalite Saint Louis foram registrados em humanos, sendo isoladas três cepas do vírus, do sangue desses pacientes, que não manifestaram sinais neurológicos (RODRIGUES et al., 2010a, 2010b). No ano de 2006, em São José do Rio Preto, também no estado de São Paulo, foi declarado um surto de encefalite Saint Louis concomitante a um surto causado por DENV-3 (vírus da dengue), com 21 casos confirmados (MONDINI et al., 2007a). Em 2014, um caso foi identificado em um paciente suspeito de dengue em Ribeirão Preto (SP) (MAIA et al., 2014). A infecção pelo SLEV pode não ser rara em humanos, mas é frequentemente confundida com o vírus da dengue (DENV) e não é diagnosticada no Brasil (MONDINI et al., 2007b).

Os resultados encontrados demonstram a importância dos inquéritos epidemiológicos utilizando cavalos como sentinelas, para acompanhamento dessas zoonoses, como uma estratégia de vigilância epidemiológica dessas enfermidades, visando a prevenção em seres humanos. A implementação deve ser realizada a partir da necessidade e da condição do 
local, levando em consideração a vigilância sentinela, a mortandade aviária, epizootias em equinos, vigilância entomológica e a deteç̧ão precoce de casos em humanos (BRASIL, 2009; MARTÍNEZ et al., 2002).

Diante da relevância das zoonoses pesquisadas para a saúde pública, torna-se evidente a necessidade da manutenção deste tipo de vigilância sanitária na região, de modo a desenvolver e implementar programas sanitários baseados na prevenção e controle dessas enfermidades.

\section{CONCLUSÃO}

Foi verificada alta soroprevalência para Leptospira interrogans e detectados equinos com anticorpos para vírus do gênero Flavivirus na cidade de Pelotas e arredores, no estado do Rio Grande do Sul.

\section{SEROPREVALENCE OF Leptospira interrogans AND FLAVIVIROSIS IN HORSES FROM THE CITY OF PELOTAS AND SURROUNDINGS, IN RIO GRANDE DO SUL}

\section{ABSTRACT}

eptospirosis and flavivirosis that affect horses are zoonoss of worldwide occurrence and of great importance in public health. Therefore, the objective of this study was to provide an epidemiological survey through serological examination for screening of Leptospira spp. and flavivirosis in the region of Pelotas/ RS and surroundings. For this, blood samples were collected from 275 horses, from these, 119 were cart load animals from Pelotas - Brazil and 156 were untied animals seized on the highways within the city of Pelotas and Capão do Leão - Brazil. For the serological diagnosis of leptospirosis, Microscopic Agglutination Test (MAT) was used, where $100 \%$ of the samples tested showed a minimum value of 1:100 for several serovars and 4.72\% (13 animals) presented serology higher than $1: 800$ in serovars of clinical importance such as $L$. interrogans Icterohaemorrhagiae, L. interrogans Canicola and L. interrogans Grippothyphosa. In the indirect immunofluorescence test, $1.8 \%$ of seropositive animals (5 animals) were identified for flavivirosis. We can observe in this study the prevalence of Leptospira spp. in all the animals evaluated and the presence of flavivirus in the region. This confirms the importance 
of epidemiological surveys for the prevention and control of zoonoss with importance in public health.

Keywords: Leptospirosis. Flaviviridae. Horses. Epidemiology. Seroprevalence.

\section{SEROPREVALENCIA DE Leptospira interrogans Y FLAVIVIROSIS EN}

\section{EQUINOS DE LA CIUDAD DE PELOTAS Y ALREDEDORES, EN RIO GRANDE DO}

SUL

\section{RESUMEN}

a leptospirosis y las flavivirosis que afectan equinos son zoonosis de ocurrencia mundial y de gran importancia en salud pública. Por lo tanto, el objetivo de este estudio fue - poner a disposición el levantamiento epidemiológico a través de un examen serológico para la clasificación de Leptospira spp. y flavivirosis en la región de Pelotas/RS y alrededores. Para ello se recolectaron muestras de sangre de 275 equinos, siendo 119 animales de carrocería de la ciudad de Pelotas y 156 animales que fueron incautados sueltos en las carreteras y dentro de la ciudad de Pelotas y Capão do Leão. Para el diagnóstico serológico de leptospirosis, se utilizó el Test de Aglutinación Microscópica (MAT), 100\% de las muestras analizadas presentaron una titulación mínima de 1:100 a varios serovares, y el 4,72\% (13 animales) presentaron serología superior a 1:800 en serovares de importancia clínica como L. interrogans Icterohaemorrhagiae, L. interrogans Canicola y L. interrogans Grippothyphosa. Frente a la prueba de inmunoflorescencia indirecta fueron identificados el 1,8\% de seropositivos ( 5 animales) para flavivirosis. Se pudo observar en el estudio la prevalencia de Leptospira spp. en todos los animales evaluados y la presencia de las flavivirosis en la región. Con ello se afirma la importancia de los levantamientos epidemiológicos para prevención y control de zoonosis con importancia en salud pública.

Palabras clave: Leptospirosis. Flaviviridae. Caballos. Epidemiología. Seroprevalencia

\section{REFERÊNCIAS}

ANVISA - AGÊNCIA NACIONAL DE VIGILÂNCIA SANITÁRIA. Portaria Conjunta ANVISA/SAS № 370 DE 07/05/2014 - Dispõe sobre regulamento técnico-sanitário para o transporte de sangue e componentes. 2014. Disponível em: <http://portal.anvisa.gov.br/transporte-dematerial-biologico> .

ADLER, B.; MOCTEZUMA, A. P. Leptospira. In: GYLES, G. L.; PRESCOTT, J. F.; SONGER, G.; THOEN, C. O. Pathogenesis of bacterial infections in animals. 4. ed. lowa: Blackwell 
Publishing, p. 527-547, 2010.

ARAUJO, F. A. A. Inquéritos sorológicos em equídeos e aves silvestres para detecção de anticorpos anti-arbovírus de importância em saúde pública no Brasil. Goiânia: UFG, 2011. 149p. Tese (Doutorado em Ciência Animal), Programa de Pós-Graduação em Ciência Animal, Escola de Veterinária e Zootecnia, Universidade Federal de Goiás, 2011.

ARENHART, S.; WEIBLEN, R.; FLORES, E.; GIL, L. H. V. Construction of a chimeric yellow fever virus 17-D expressing the prM/E proteins of West Nile virus by homologous recombination in yeast. In: Brazilian Congress of Virology \& VII Mercosur Meeting of Virology, 23, 2012, Foz do Iguaçu. ANNALS. Foz do Iguaçu: Virus reviews \& research, v.17, n. 2, Suppl. 1, p. 416, 2012. Disponível em: <http://157.86.113.86/index.php/vrrjournal/article/view/78/77> .

BAVERUD, V.; GUNNARSSON, A.; ENGVALL, E. O.; FRAZÉN, P.; EGENVALL, A. Leptospira seroprevalence and association between seropositivy, clinical disease and host factors in horses. Acta Veterinaria Scandinavica, v. 51, n. 15, 2009.

BLAZIUS, R. D.; ROMÃO, P. R. T.; BLAZIUS, E. M. C. G.; et al. Ocorrência de cães errantes soropositivos para Leptospira spp. na cidade de Itapema, Santa Catarina, Brasil. Caderno de Saúde Pública, Rio de Janeiro, v. 21, n. 6, p. 1952-1956, 2005.

BRASIL. MINISTÉRIO DA SAÚDE. Secretaria de Vigilância em Saúde. Departamento de Vigilância Epidemiológica. Guia de Vigilância Epidemiológica. 7. ed. Caderno 9, p. 43-48, 2009. 816p. Disponível em:

<http://bvsms.saude.gov.br/bvs/publicacoes/guia_vigilancia_epidemiologica_7ed.pdf> .

BRASIL. MINISTÉRIO DA SAÚDE. Secretaria de Vigilância em Saúde. Departamento de Vigilância das Doenças Transmissíveis. Leptospirose: diagnóstico e manejo clínico. Brasília: Ministério da Saúde, 2014a. 44p. Disponível em:

<http://portalarquivos.saude.gov.br/images/pdf/2014/dezembro/02/Miolo-manualLeptospirose-17-9-2014.pdf> .

BRASIL - MINISTÉRIO DA SAÚDE. Blog da Saúde. Febre do Nilo. 2014b. Disponível em: <http://www.brasil.gov.br/editoria/saude/2014/12/ministerio-da-saude-confirma-primeirocaso-de-febre-do-nilo> .

BRASIL. MINISTÉRIO DA SAÚDE. Leptospirose. Guia de Vigilância em saúde. Secretaria de Vigilância em Saúde. Brasília. Coordenação-Geral de Desenvolvimento da Epidemiologia em Serviços. 2. ed. p. 59-588, 2017. Disponível em:

http://portalarquivos.saude.gov.br/images/pdf/2017/outubro/06/Volume-Unico-2017.pdf .

BRASIL. MINISTÉRIO DA SAÚDE. Monitoramento da Febre do Nilo Ocidental, Brasil e

Espírito Santo - 2018. Informe n. 1, 2017/2018. 2018. Disponível em:

<http://portalarquivos2.saude.gov.br/images/pdf/2018/agosto/29/INFORME-01-FNO-2018SE-31-22ago18.pdf> . 
CASSEB, A. R.; CASSEB, L. M. N.; SILVA, S. P.; VASCONCELOS, P. F. C. Arbovírus: Importante Zoonose na Amazônia Brasileira. Veterinária e Zootecnia, v. 20, n. 3, p. 391-403, 2013.

CHALHOUB, F. L. L. Investigação da circulação dos vírus da encefalite de Saint Louis e do Oeste do Nilo em equinos do estado do Rio de Janeiro. Rio de janeiro: IOC, 2017. 76p. Dissertação (Mestrado em Medicina Tropical), Fundação Oswaldo Cruz, Instituto Oswaldo Cruz, 2017.

ELLIS, W. A. Leptospirosis as cause of reproductive failure. Veterinary Clinics of North America: Food and animal practice, v. 10, n. 3, p. 463-478, 1994.

FAINE, S. B.; ADLER, B.; BOLIN, C.; et al. Leptospira and leptospirosis. 2. ed. Melbourne: MediSci, 1999. 296p.

FARACO, B. C.; SEMINOTTI, N. A Relação Homem - Animal e a Prática Veterinária. Revista CFMV, Brasília, v. 10, n. 32, p. 57-62, 2004.

FIGUEIREDO, L. T. M. Emergent arboviruses in Brazil. Revista da Sociedade Brasileira de Medicina Tropical, v. 40, n. 2, p. 224-229, 2007.

FLORES, F. E.; WEIBLEN, R. O Vírus do Nilo Ocidental - Revisão Bibliográfica. Ciência Rural, Santa Maria, v. 39, n. 2, p. 604-612, 2009.

FUNASA - FUNDAÇÃO NACIONAL DE SAÚDE. Manual de Leptospirose. 3. ed. Brasília: Gerência Técnica de Editoração, 1997. 89p.

GOMES, A. D. C. Vigilância Entomológica. Informe Epidemiológico do SUS, v. 11, p. 79-90. 2002.

GOULD, E. A.; DE LAMBALLERIE, X.; ZANOTTO, P. M.; et al. Origins, evolution, and vector/host coadaptations within the genus Flavivirus. Advances in Virus Research, v. 59, p. 277-314, 2003.

HAGIWARA, M. K. Leptospirose canina. Boletim Técnico - Pfizer Saúde Animal, p. 1-6, 2003. Disponível em: <file://C:/Users/pricc/Downloads/Boletim_Leptospirose.pdf> .

HAMOND, C.; MARTINS, G.; LAWSON-FERREIRA, R.; et al. The role of horses in the transmission of leptospirosis in an urban tropical area. Epidemiology and Infection, v. 141, n. 1, p. 33-35, 2012.

HEINEN, L. B. S.; ZUCHI, N.; SERRA, O. P.; et al. Saint Louis encephalitis virus in Mato Grosso, Central-Western, Brazil. Revista do Instituto de Medicina Tropical de São Paulo, v. 57, n. 3, p. 215-220, 2015. 
ICTV - INTERNATIONAL COMMITTEE ON TAXONOMY OF VIRUSES. Virus Taxonomy: Flaviviridae. 2018. Disponível em: https://talk.ictvonline.org/taxonomy/ .

JONES, T. C.; HUNT, R. D.; KING, N. W. Patologia veterinária. 6. ed. São Paulo: Editora Manole, 2000. 141p.

KOMAR, N.; CLARK, G. G. West Nile virus activity in Latin America and the Caribbean. Revista Panamericana de Salud Publica, v. 19, p. 112-117, 2006.

LILEBAUM, W.; SANTOS, M. R. C.; BARBOSA, A. V. Leptospirose em reprodução animal: II. Bovinos do estado do Rio de Janeiro, Brasil. Revista Brasileira de Ciências Veterinárias, v. 2, n. 1, p. 1-6, 1995. Disponível em: <http://doi.editoracubo.com.br/10.4322/rbcv.2015.011>.

MAIA, F. G. M.; CHÁVEZ, J. H.; SOUZA, W. M.; et al. Infection with Saint Louis encephalitis virus in the city of Ribeirao Preto, Brazil: report of one case. International Journal of Infectious Diseases, v. 26, p. 96-97, 2014.

MARTínEZ, L. A. D.; MANRIQUE, F. M. C.; MUÑOZ, G. Apuntes para el desarrollo de sistemas de vigilancia para la detección precoz del Virus del Oeste del Nilo. Infectio, v. 6, n. 4, p. 226234, 2002.

MARTINS, F. S. V.; CASTIÑEIRAS, T. M. P. P. Leptospirose. Centro de informação em saúde para viajantes, 2009. Disponível em:

<http://www.cives.ufrj.br/informacao/leptospirose/lep-iv.html> .

MELANDRI, V.; GUIMARÃES, A. E.; KOMAR, N.; NOGUEIRA, M. L.; MONDINI, A.; FERNANDEZSESMA, A.; ALENCAR, J.; BOSCH, I. Serological detection of West Nile virus in horses and chicken from Pantanal, Brazil. Memórias do Instituto Oswaldo Cruz, v. 107, n. 8, p. 10731075, 2012.

MIRAGLIA, F. Molecular and serological characterization of Leptospira interrogans serovar Canicola isolated from dogs, swine, and bovine in Brazil. Tropical Animal Health and Production, v. 45, n. 1, p. 117-121, 2013.

MONDINI, A.; BRONZONI, R. V. M.; CARDEAL, I. L. S.; et al. Simultaneous infection by DENV-3 and SLEV in Brazil. Journal of Clinical Virology, v. 40, n. 1, p. 84-86, 2007a.

MONDINI, A.; CARDEAL, I. L. S.; LÁZARO, E.; et al. Saint Louis encephalitis virus, Brazil.

Emerging Infectious Diseases, v. 13, n. 1, p. 176-178, 2007b.

OLIVEIRA, A. C.; BARBOSA, A. E. A.; SOUSA, E. B. A.; et al. Relatório Anual de Rotas e Áreas de Concentração de Aves Migratórias no Brasil - 2016. Instituto Chico Mendes de Conservação da Biodiversidade. 63p. 2016. Disponível em:

<http://www.icmbio.gov.br/portal/images/stories/DCOM_Miolo_Rotas_Migrat\%C3\%B3rias_ 2016_final.pdf>. 
OSTLUND, E. N.; CROM, R. L.; PEDERSEN, D. D.; et al. Equine West Nile encephalitis, United States. Emerging Infectious Diseases, v. 7, n. 4, p. 665-669, 2001.

PACCA, C. C. Screening de novos antivirais inibidores de flavivírus. São José do Rio Preto: FAMERP, 2013. 75p. Tese (Doutorado em Ciências da Saúde), Faculdade de Medicina de São José do Rio Preto, 2013.

PAPPAS, G.; CASCIO, A. Optimal treatment of leptospirosis: queries and projections. International Journal of Antimicrobial Agents, v. 28, n. 6, p. 491-496, 2006.

PAUVOLID-CORRÊA, A.; TAVARES, F. N.; COSTA, E. V.; et al. Serologic evidence of the recent circulation of Saint Louis encephalitis virus and high prevalence of equine encephalitis viruses in horses in the Nhecolândia sub-region in South Pantanal, Central-West Brazil. Memórias do Instituto Oswaldo Cruz, v. 105, n. 6, p. 829-833, 2010.

PAUVOLID-CORRÊA, A.; MORALES, M. A.; LEVIS, S.; et al. Neutralising antibodies for West Nile virus in horses from Brazilian Pantanal. Memórias do Instituto Oswaldo Cruz, v. 106, n. 4, p. 467-474, 2011.

PIMENTEL, J. S.; GENNARI, S. M.; DUBEY, J. P.; et al. Inquérito sorológico para toxoplasmose e leptospirose em mamíferos selvagens neotropicais do Zoológico de Aracaju, Sergipe.

Pesquisa Veterinária Brasileira, v. 29, n. 12, p. 1009-1014, 2009.

REICZIGEL, J.; FOLDI, J.; OZSVARI, L. Exact confidence limits for prevalence of a disease with an imperfect diagnostic test. Epidemiology and Infection, v. 138.n. 11 p. 1674-1678, 2010.

RODRIGUES, S. G.; NUNES, M. R. T.; CASSEB, S. M. M.; et al. Molecular epidemiology of Saint Louis encephalitis virus in the Brazilian Amazon: genetic divergence and dispersal. Journal of General Virology, v. 91, n. 10, p. 2420-2427, 2010a.

RODRIGUES, S. G.; OLIVA, O. P.; ARAUJO, F. A. A.; et al. Epidemiology of Saint Louis encephalitis virus in the Brazilian Amazon region and in the State of Mato Grosso do Sul, Brazil: elevated prevalence of antibodies in horses. Revista Pan-Amazônica de Saúde, v. 1, n. 1, p. 81-86, 2010b.

ROSA, R.; COSTA, E. A.; MARQUES, R. E.; et al. Isolation of Saint Louis encephalitis virus from a horse with neurological disease in Brazil. PLOS Neglected Tropical Diseases, v. 7, p. e2537, 2013.

SANTA ROSA, C. A. Diagnóstico laboratorial das leptospiroses. Revista Microbiológica, v. 1, n. 2, p. 97-109, 1970.

SBPC - SOCIEDADE BRASILEIRA DE PATOLOGIA CLÍNICA. Posicionamento oficial da Sociedade Brasileira de Patologia Clínica/Medicina Laboratorial referente ao diagnóstico 
laboratorial do Zika vírus, 2016. Disponível em:

<http://www.sbpc.org.br/upload/conteudo/sbpcml_posicionamento_zika_virus.pdf> .

SCHMIDT, P.L. Companion Animals as Sentinels for Public Health. Veterinary Clinics of North America: Small Animal Practice, v. 39, n. 2, p. 241-250, 2009.

SERGEANT, E. S. G. Epitools epidemiological calculators. Ausvet Pty Ltd. 2018. Disponível em: <http://epitools.ausvet.com.au> .

SESA - SECRETARIA DE ESTADO DA SAÚDE DO ESPÍRITO SANTO. SESA confirma caso de Febre do Nilo. 2018. Disponível em: <https://saude.es.gov.br/Not\%C3\%ADcia/sesaconfirma-caso-de-febre-do-nilo> .

SESAPI - SECRETARIA DE ESTADO DA SAÚDE DO PIAUÍ. Portal da Saúde. Nota - Febre do Nilo Ocidental. 2017. Disponível em: <http://www.saude.pi.gov.br/noticias/2017-0615/8057/nota-febre-do-nilo- ocidental.html> .

SESAPI - SECRETARIA DE ESTADO DA SAÚDE DO PIAUÍ. Portal da Saúde. Nota sobre a ocorrência de Febre do Nilo Ocidental no estado. 2019. Disponível em:

<http://www.saude.pi.gov.br/noticias/2019-02-08/8933/nota-sobre-a-ocorrencia-de-febredo-nilo-ocidental-no-estado.html .

SILVA, E. F.; SANTOS, C. S.; ATHANAZIO, D. A.; et.al. Characterization of virulence of Leptospira isolates in a hamster model. Vaccine, v. 26, n. 31, p. 3892-3896, 2008.

SILVA, J. R. Pesquisa de infecções por Flavivírus da encefalite de Saint Louis, Rocio e Oeste do Nilo em cavalos, por inquérito sorológico e de isolamento viral. São Paulo: USP, 2010. 131p. Dissertação (Mestrado), Faculdade de Medicina de Ribeirão Preto, Universidade de São Paulo; 2010.

SILVA, J. R.; MEDEIROS, L. C.; REIS, V. P.; et al. Serologic survey of West Nile virus in horses from Central-West, Northeast and Southeast Brazil. Memórias do Instituto Oswaldo Cruz, v. 108, n. 7, p. 921-923, 2013.

SPEIRS, V. C. Exame Clínico de Equinos. Porto Alegre: Artmed, 1999. 366p.

TROCK, S. C.; MEADE, B. J.; GLASER, A.; et al. West Nile virus outbreak among horses in New York state, 1999 and 2000. Emerging Infectious Diseases, v. 7, n. 4, p. 745-747, 2001.

VELHO, J. R.; LINS, L. A.; BRUM, C. S.; et al. Inserção do Médico Veterinário nas Comunidades Carentes de Pelotas-RS. In: SALÃO DE EXTENSÃO E CULTURA, 2, 2007, Pelotas. ANAIS. Pelotas, UFPEL, 2007.

VIANNA, R. S. T. Inquéritos soroepidemiológico em equinos da região sul do Brasil para detecção de anticorpos anti-flavivirus de interesse em saúde pública. Goiânia: UFG, 2010. 
49p. Dissertação (Mestrado em Medicina Veterinária), Programa de Pós-Graduação em Medicina Veterinária, Universidade Federal de Goiás, 2010.

WHO - WORLD HEALTH ORGANIZATION. Human Leptospirosis: Guidance for Diagnosis, Surveillance and Control. Geneva: World Health Organization, 2003. 109p. Disponível em: <http://www.who.int/iris/handle/10665/42667>.

Autor para correspondência: Jemhally Dillenburg Hack. Hospital de Clínicas Veterinárias, Faculdade de Veterinária, Universidade Federal de Pelotas, caixa postal 354,

Campus Universitário, CEP 96010-900, Capão do Leão (RS). jemhally@yahoo.com.br 